\title{
CAPTURAS DE TELA
}

\section{3}

RAUL MOURÃO
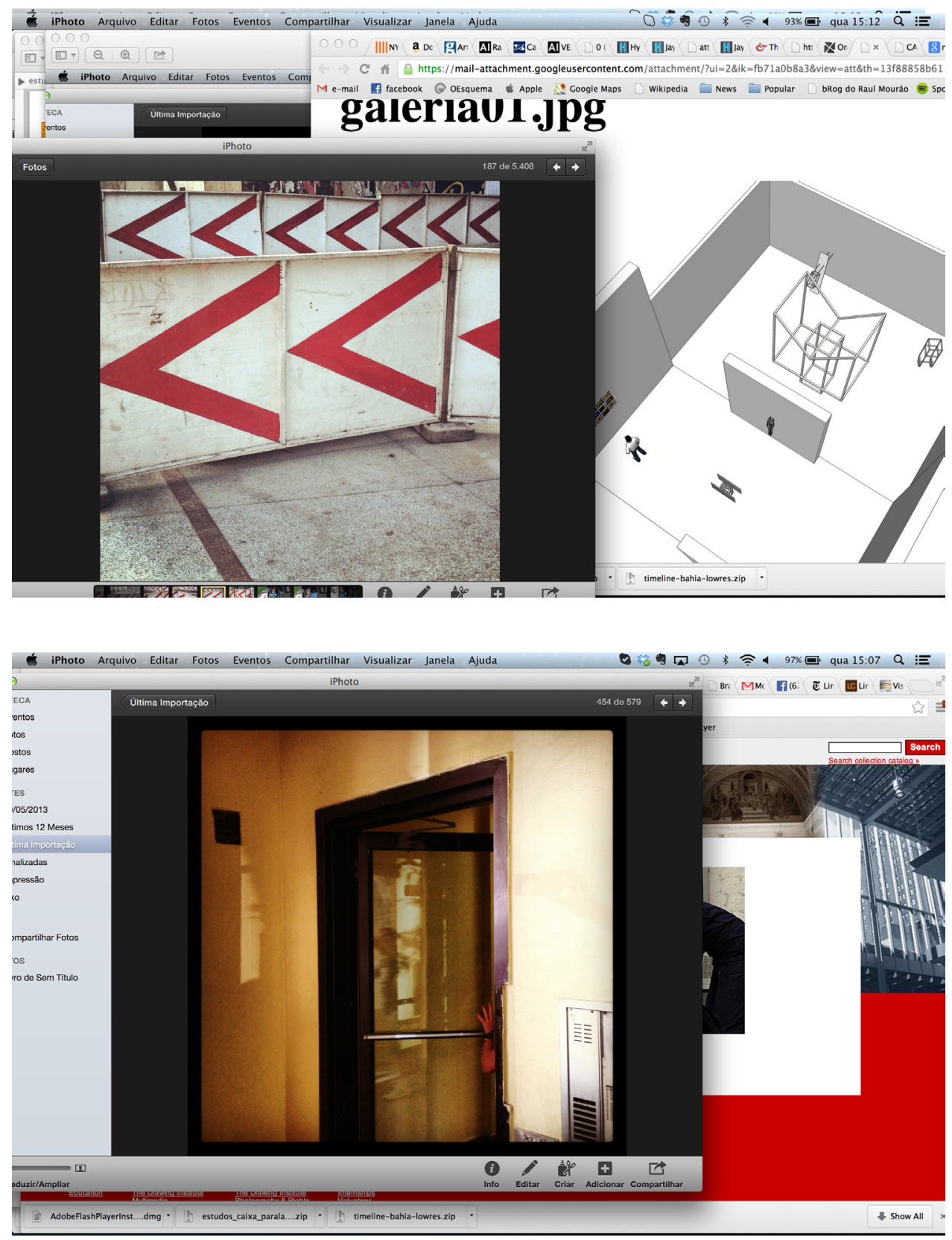

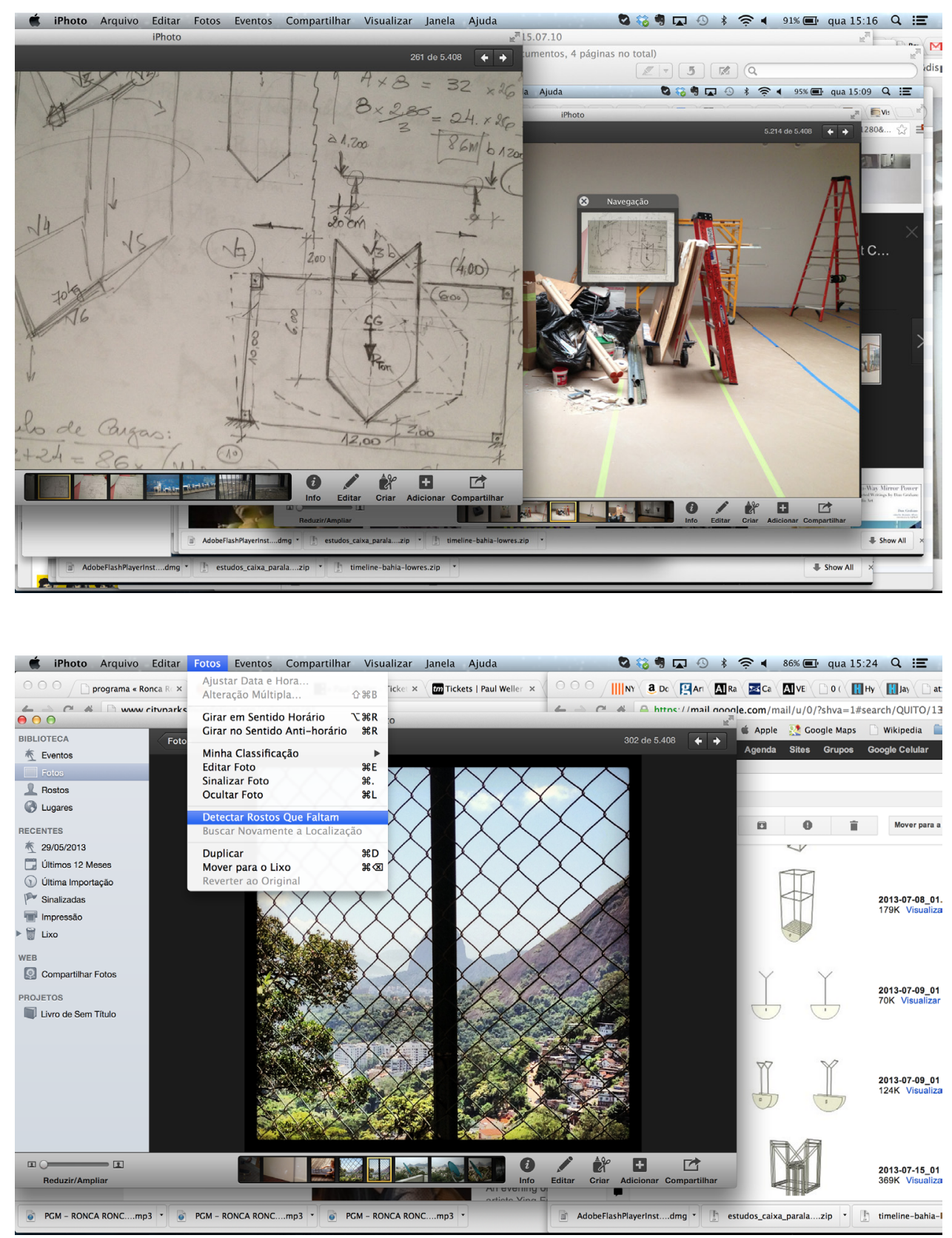

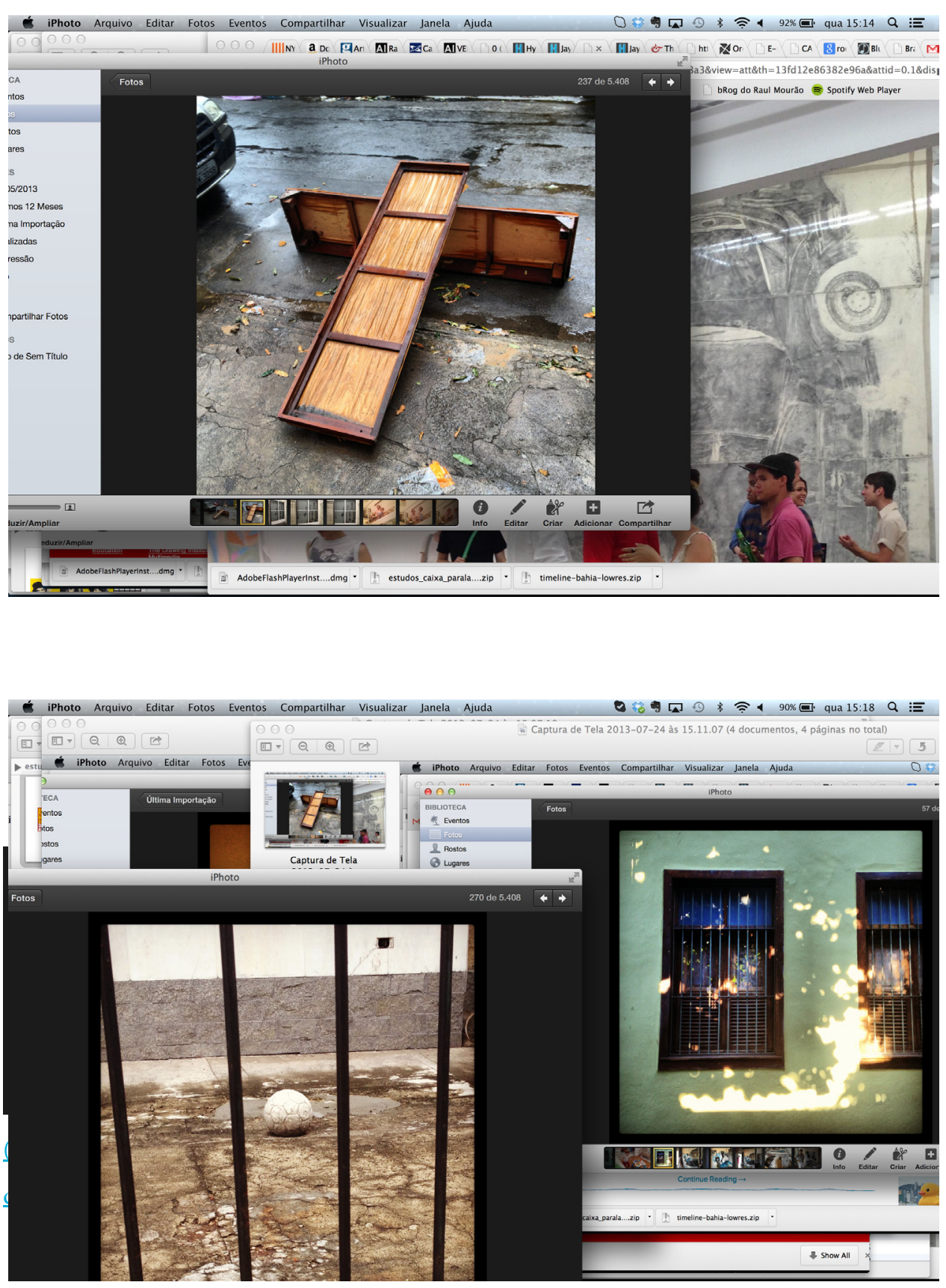

RAUL MOURão é artista plástico, expõe seus trabalhos desde 1991, abrangendo desenho, gravura, pintura, escultura, vídeo, fotografia, instalação e performance. Entre suas exposições mais recentes estão a individual Tração animal (Museu de Arte Moderna do Rio de Janeiro, 2012) e a participação na coletiva From the margin to the edge (Sommerset House, Londres, Inglaterra, 2012). 